\title{
EHSMu: a New Ecohydrological Streamflow Model to Estimate Runoff in Urban Areas
}

\author{
Elena Cristiano ${ }^{1}$ (D) $\cdot$ Roberto Deidda ${ }^{1}$ (D) $\cdot$ Francesco Viola ${ }^{1}$ (D) \\ Received: 28 May 2020 / Accepted: 14 October 2020 / \\ Published online: 22 October 2020 \\ (C) The Author(s) 2020
}

\begin{abstract}
A conceptual lumped ecohydrological streamflow model (EHSMu) is presented as a promising tool to simulate runoff in urban catchments. The model, based on the interaction between a soil bucket and two linear reservoirs, enables also evapotranspiration and aquifer recharge to be estimated. Notwithstanding its minimalism, EHSMu describes interactions among soil moisture dynamics, hydrological fluxes and ecological processes. The model was calibrated and validated within two densely urbanized sub-basins in Charlotte (US). A Monte Carlo procedure is used to investigate the efficiency of random sets of 8 model parameters. Results show the high model performance $(\mathrm{NSE}=0.72)$. The influence of land use change is evaluated, by varying the imperviousness and crop coefficients. Synthetic experiments show that increasing urbanization triggers a linear decrease in evapotranspiration and aquifer recharge, while it increases the fast runoff. An opposite response is achieved by installing vegetation with higher potential evapotranspiration, which would contribute to the actual evapotranspiration making up $50-55 \%$ of the total water balance.
\end{abstract}

Keywords Hydrological modelling · Rainfall-runoff modelling · Ecohydrology · Urban areas

\section{Introduction}

Over the last decades, people have been moving to cities, contributing to an increase in urbanization, which is projected to keep growing in the future (UN Desa 2019). This is expected to lead to an increment in the runoff generation and, consequently, to an intensification of flood risk. In this framework, modelling can play a significant role in the runoff estimation and in the definition of flood mitigation strategies.

Elena Cristiano

elena.cristiano@unica.it

1 Department of Civil and Environmental Engineering and Architecture, University of Cagliari,

Cagliari, CA, Italy 
Urban areas, however, are complex systems and, due to the high spatial variability and heterogeneity, they are difficult to model (Fletcher et al. 2013; Salvadore et al. 2015). Several models have been proposed to estimate the urban runoff, trying to account for spatial and temporal variability of rainfall and catchment (Cristiano et al. 2017). Most of these models focus on the identification and representation of the stormwater drainage network (Zoppou 2001), and they combine it with surface dynamics, in order to estimate the amount of rainfall that reaches the sewer system (Bermúdez et al. 2018; Rubinato et al. 2013; Versini et al. 2016). Semi- and fully-distributed physically-based models have been developed for many urban areas, showing good performance in the runoff estimation (Aronica and Cannarozzo 2000; Pina et al. 2016). However, in most of the cases, these models require a long computational time and also spatially and temporally distributed input data (Cristiano et al. 2017). The choice of the most suitable model is constrained by the data availability and final goals. Berne et al. (2004) suggested a criterion based on the relation between available rainfall resolution and catchment area: if the rainfall resolution is larger than the catchment area, a conceptual modelling approach is suggested, otherwise, a distributed approach could be more efficient. In the case of a lack of distributed data or a necessity of fast simulations, conceptual models would be preferable. Sarma et al. (1973) compared different conceptual rainfall-runoff model performances in urban areas and showed that, for small basins, the single linear reservoir leads to good runoff estimation. These models, however, do not account for other components, such as evapotranspiration, subsurface flow and aquifer recharge.

The combination of hydrological and ecological elements within ecohydrological models has been explored in depth for natural environments and the importance of taking into account both components has been largely underlined (Botter et al. 2007; Laio et al. 2001; RodriguezIturbe et al. 1999). In urban areas, this aspect has recently become more popular: to guarantee a sustainable management of soil and water resources, a better understanding of the whole urban ecosystem is required (Marchionni et al. 2019). Investigating hydrological and ecological processes and their interactions provides a strong support for urban design and water management (Li 2012). Recently, Meili et al. (2020) proposed an urban ecohydrological model, Urban Tethys-Chloris (UT\&C), which couples energy and water balance and combines principles of ecosystem modelling with an urban canopy scheme. UT\&C explicitly accounts for the biophysical and ecophysiological characteristics of roof vegetation, ground vegetation and urban trees in simulating water and energy fluxes.

Many ecohydrological urban models focus on small scale, investigating the interactions among impervious surfaces, vegetation, and atmosphere in urban areas (Grimmond et al. 2010; Marchionni et al. 2019; Vico et al. 2014). At the moment, however, only a few ecohydrological models have been developed at catchment scale (Liu et al. 2013; Shields and Tague 2015) and the integration of ecohydrological processes to define the runoff generation at urban scale needs to be further investigated.

In this context, we introduce a new parsimonious lumped conceptual ecohydrological streamflow model for urban areas (EHSMu) to estimate the runoff generation in an urban environment, taking into account water-soil dynamics, vegetation types, evapotranspiration fluxes and aquifer recharge. The model, described in Section 2, combines a soil bucket and two linear reservoirs, to simulate the runoff at the catchment outlet and to estimate evapotranspiration and aquifer recharge. Two catchments in the Charlotte metropolitan areas (US) were chosen as case studies to calibrate and validate the model, using rainfall and potential evapotranspiration at hourly scale as input for the model. Rainfall and streamflow data have been used in previous studies to investigate the urban hydrological response in relation to 
storm characteristics and flood frequencies (Cristiano et al. 2019; ten Veldhuis et al. 2018; Wright et al. 2014), and they have shown good reliability, with high rainfall-runoff correlation. Results are discussed in Section 3, where the impact of land use and land cover changes is investigated through a sensitivity analysis.

\section{Methodology}

\subsection{Model Description}

The EHSMu model is based on a simple schematization of physical elements within an urban catchment and on several hypotheses regarding water fluxes. Urban areas are described as a lumped ensemble of impervious (roads, roofs) and pervious (gardens, parks) surfaces. When rain falls over impermeable surfaces, it is supposed to be directly transferred towards the drainage system, in a time depending on the catchment area and drainage network geometry and materials (Al-Janabi et al. 2019). The rain falling over permeable areas drives soil moisture dynamics, which frame evapotranspiration rates, excess runoff generation and leakage occurrences. The latter are supposed to partially feed deep aquifers, thus introducing a new element to the water balance.

The hydrological scheme of the urban basin, implemented in EHSMu and presented in Fig. 1, is defined as the combination of three interconnected elements: a soil bucket below the permeable area and two linear reservoirs, named fast and slow reservoir respectively. The fast reservoir collects both the runoff from impermeable areas $\left(Q_{i m p}\right)$ and runoff generated by the saturation excess in the permeable areas $\left(Q_{\text {exc }}\right)$. The slow reservoir receives as input a fraction $c_{1}$ of the percolation leakage $L$ originated from the soil bucket below the permeable area, while the component $\left(1-c_{1}\right) L$ infiltrates the aquifer. The total outflow runoff $Q_{\text {out }}$ is defined as the combination of the fluxes deriving from the fast and slow reservoir.

\subsubsection{Soil Water Balance}

Hourly rainfall depth $R(\mathrm{~mm} / \mathrm{h})$ is considered as the main climatic forcing and it is used as input for the model as a time series spatially averaged over the catchment. As mentioned in the Model description, rainfall is partitioned between an impermeable fraction $c_{0}$ and a permeable fraction $\left(1-c_{0}\right)$, where water fluxes between atmosphere and soil bucket may occur through rainfall infiltration and evapotranspiration processes, affecting the balance of soil moisture $s$. Interception by vegetation is assumed to be negligible, since the contribution over a long time series in urban areas is often quite small compared to the other fluxes (Zabret and Šraj 2019). The permeable fraction of soil is characterized by the soil porosity $n$ and by the root depth $Z_{r}$, whose product $n Z_{r}(\mathrm{~mm})$, often referred to as "active soil depth", is a parameter of the model.

The assessment of relative soil moisture variations $\Delta s$ in the permeable part of the soil bucket during an hourly temporal step is achieved with the numerical solution of the following water balance equation carried out through a forward finite differences method:

$$
\frac{\Delta s}{\Delta t}=\frac{1}{\left(1-c_{0}\right) n Z r}\left(\left(1-c_{0}\right) R-Q_{e x c}-E T-L\right)
$$

where soil moisture $s$ is defined as the dimensionless ratio between the soil water volume and the soil control volume, $Q_{e x c}(\mathrm{~mm})$ is the runoff generated by saturation excess and $E T(\mathrm{~mm})$ 


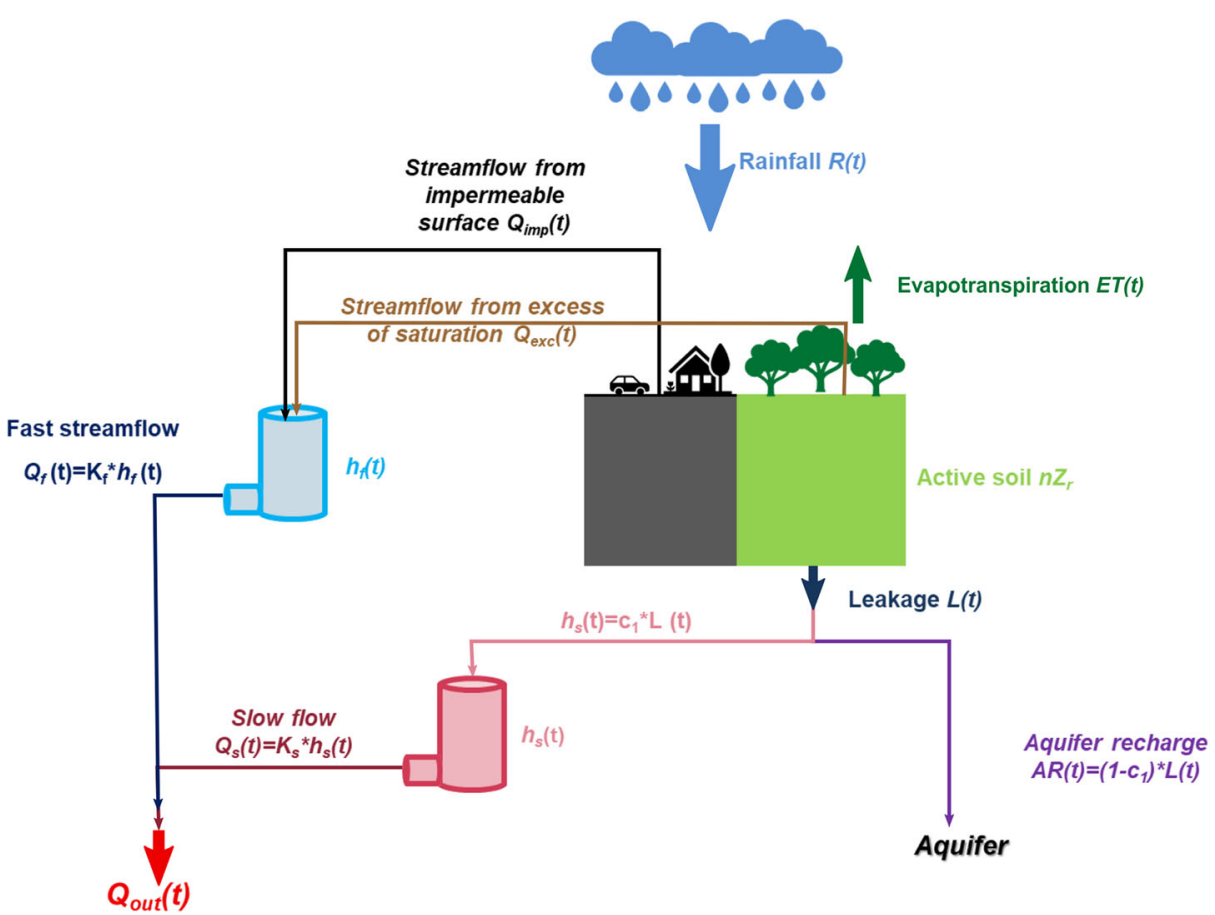

Fig. 1 Schematic representation of the hydrological processes implemented in EHSMu

and $L(\mathrm{~mm})$ represent the soil water losses due to evapotranspiration and leakage, which will be described in the next section. In particular, $Q_{\text {exc }}$ is produced when the rainfall exceeds the maximum storage capacity of the permeable soil.

\subsubsection{Loss Components: Evapotranspiration and Percolation Leakage}

In ecohydrology, evapotranspiration is one of the most critical processes to represent: its interdependency with the soil moisture plays a significant role in the modelling (Asbjornsen et al. 2011) and it has often been modelled as a stepwise function (Laio et al. 2001; Pumo et al. 2008; Viola et al. 2008). Maximum evapotranspiration $E_{\max }$ generally occurs when the soil water content is above the soil field capacity $s_{l}$ : in these conditions the plant living processes are guaranteed. The complex relations between evapotranspiration and soil water content are often modelled through a simplified approach by assuming that, as soil moisture decreases to the hygroscopic point $s_{0}$, evapotranspiration linearly decreases from $E_{\max }$ to zero (Hale and Orcutt 1987). Under this simplified framework, in the EHSMu model, evapotranspiration is assumed to be governed by the following Eq. 2 as a function of soil water content $s$.

$$
E T(s)=\left\{\begin{array}{cc}
0 & \text { if } s \leq s_{0} \\
E_{\max }\left(\frac{s-s_{0}}{s_{l}-s_{0}}\right)\left(1-c_{0}\right) & \text { if } s_{0}<s \leq s_{l} \\
E_{\max }\left(1-c_{0}\right) & \text { if } s>s_{l}
\end{array}\right.
$$

Following the FAO-56 Penman-Monteith method described in Allen et al. (1998) and widely used in literature, the maximum evapotranspiration rate $E_{\max }$ was derived as a function of the 
reference evapotranspiration ET0. This value depends on several factors, such as solar radiation, air temperature, humidity and wind speed. The maximum evapotranspiration rate can be obtained as the product of the reference evapotranspiration ET0 and the crop coefficient $K_{c}$, which is a characteristic value of the vegetation type and can be easily derived from agronomy literature (Allen et al. 1998). This approach has been integrated in EHSMu, where the crop coefficient $K_{c}$ is a parameter to be calibrated, due to the high variability in urban areas.

In addition to evapotranspiration, losses derived from percolation leakage are mainly controlled by the hydraulic conductivity, which varies depending on the soil moisture. If the soil water content is below the soil field capacity, the hydraulic conductivity is null and, from that point, we assume that it linearly increases to a maximum in correspondence with the soil saturation (Clapp and Hornberger 1978). This schematization enables the presence of macro porosity and fractures in the soil to be represented, which may lead water directly to deep aquifers. According to this simplified framework, the percolation leakage can be estimated with the following equation:

$$
L(s)=\left\{\begin{array}{cl}
0 & \text { if } s \leq s_{l} \\
\left(s-s_{l}\right) n Z r\left(1-c_{0}\right) & \text { if } s>s_{l}
\end{array}\right.
$$

It is worth mentioning that, although the leakage process is here represented as a pulse function, with instantaneous transfer from the soil bucket to the slow reservoir at each hourly time step, the exponential recession response of the reservoir itself mitigates errors that could arise from this approximation (Viola et al. 2014).

\subsubsection{Runoff}

In EHSMu, the runoff generated at the catchment outlet $Q_{\text {out }}$ derives from the combination of the contribution of fast and slow linear reservoirs. This choice was supported by several studies, which largely discussed the number of linear reservoirs required to model properly the catchment outflow (Chow 1964; Jakeman et al. 1990).

The runoff from impervious surface, $Q_{i m p}$, and the one from the excess saturation, $Q_{e x c}$, originating from the soil bucket surface, are routed in the fast reservoir, characterized by a residence time $1 / K_{f}$. The outflow from this reservoir, $Q_{f}$, is assumed to be a linear function of the water storage $h_{f}$, and it is defined as:

$$
Q_{f}(t)=K_{f} * h_{f}(t)
$$

This reservoir represents the quick hydrological response of the basin, where the residence time $1 / K_{f}$ is expected to be close to the basin concentration time, generally less than a day.

The second linear reservoir is characterized by a longer residence time $1 / K_{s}$, and it is fed by a fraction $c_{1}$ of the leakage from the soil bucket. The outflow from the slow reservoir $Q_{s}$ can be expressed, again, as a linear function of the water stored $h_{s}$ :

$$
Q_{s}(t)=K_{s} * h_{s}(t)
$$

Considering that the second reservoir is introduced to describe the slow hydrological response of the catchment, the residence time $1 / K_{s}$ is expected to be in the order of a few days. Hence, the total runoff at the catchment outlet can be written as:

$$
Q_{\text {out }}(t)=Q_{f}(t)+Q_{s}(t)=K_{f} * h_{f}(t)+K_{s} * h_{s}(t)
$$




\subsection{Study Case}

The Charlotte metropolitan area (North Carolina, US) was chosen as a case study. In particular, Little Sugar Creek (\#507; $\left.111 \mathrm{~km}^{2}\right)$ and Little Hope $\left(\# 470 ; 7 \mathrm{~km}^{2}\right)$ were selected to investigate the applicability of the EHSMu on two basins with different extensions (Fig. 2). Land use and cover data have been derived from high-resolution $(30 \mathrm{~m})$ gridded datasets, available from the American National Land Cover Dataset NLCD. The investigated basins are highly urbanized, with almost $30 \%$ of the area covered with medium or high intensity urbanization (Fig. 2b).

Rainfall data were obtained exploiting a network of 72 tipping-bucket type rain gauges, maintained by the United States Geological Survey (USGS), which covers the Charlotte metropolitan area and provides data with a 15-min temporal resolution. Eight stations from the mentioned network (Fig. 2a, red dots) were selected, choosing the ones that have a higher spatial influence and can provide a continuous data set. Streamflow data, measured at the hydrological outlet of each sub-catchment (Fig. 2a, blue square), can be accessed through the USGS website and can be downloaded with a temporal resolution of $15 \mathrm{~min}$. A 15-year time series, from 1st January 2001 to 1st October 2015, was selected for both rainfall and streamflow data and aggregated to an hourly time step to feed the model.

Potential evapotranspiration was estimated with the Thornthwaite equation (Thornthwaite 1948), using monthly average temperature $T_{i}$, downloaded from the Global Historical Climate Network (GHCN) (Menne et al. 2012) at daily scale. The weather station located at the Charlotte airport was chosen to obtain the temperature data needed to estimate the potential evapotranspiration rate.

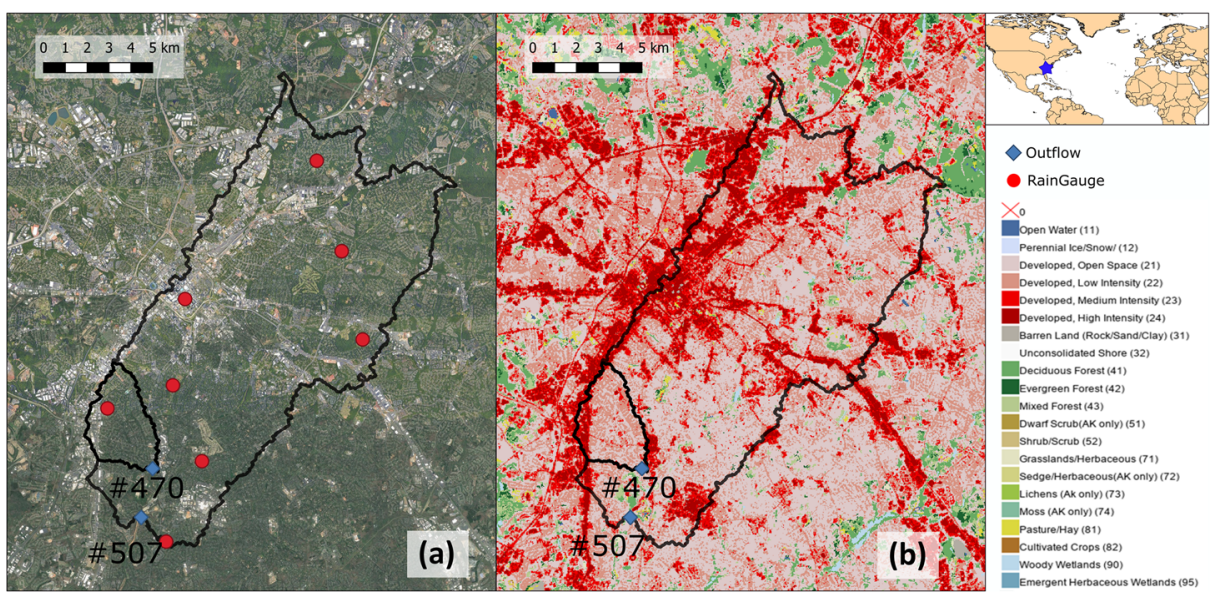

Fig. 2 Satellite map (a) and land use map (b) of the case study. Boundaries of Little Hope Creek (\#470) and Little Sugar Creek (\#507) are highlighted. (a) Red dots on the Google Satellite map indicate the rain gauge stations, blue squares stand for runoff gauging stations. (b) Map derived from http://www.mrlc.gov/: different colours represent various land covers (legend on the right inset) 


\subsection{Parameter Calibration}

The input time series were divided into two periods: the first one used for calibration and the second one for validation. For the smallest basin, \#470, the first $40 \%$ of the time series was used as the validation period and the remaining $60 \%$ as the calibration time series. This peculiar fractioning of hydrologic dataset into calibration and validation periods was motivated by the presence of a period of missing data in runoff records for the basin \#470. Since these gaps are approximately after $40 \%$ of the considered period, the longer period was used for calibration purposes and the shorter one for validation.

EHSMu requires a set of 8 parameters to represent the hydrological behaviour of the catchment: the active soil depth $n Z r$, the soil moisture triggering the leakage $s_{l}$ and the hygroscopic point $s_{0}$, the crop coefficient $K_{c}$, the slow and fast reservoir constants $K_{s}$ and $K_{f}$, the percentage of impervious surface $c_{0}$ and the fraction of leakage that contributes to the total runoff $c_{1}$. For each parameter a range of possible values was defined, based on literature and on a priori knowledge. The active soil depth $n Z r$ is quite difficult to identify without detailed information from pedological profiles and for this reason a large range is assumed for this parameter, which can vary between $1 \mathrm{~mm}$ and $1000 \mathrm{~mm}$. The term $s_{l}$ strongly depends on the soil characteristics and it is assumed to be between 0.3 and 0.95 , while the hygroscopic point $s_{0}$ is limited between 0 and $s_{l}$. The crop coefficient $K_{c}$ represents the potential capacity of the plants to sustain the evapotranspiration processes, under optimal weather conditions, ensuring no water stress for the vegetation. This coefficient is assumed to be equal to 1 for standard grass (Allen et al. 1998) and it is generally lower for vegetation with a Crassulacean acid metabolism, such as sedum, and higher for plants that require more water for survival (Farg et al. 2012; Guerra et al. 2016). The crop coefficient is assumed to vary between 0 and 2.5. The reservoir constants $K_{s}$ and $K_{f}$ represent the inverse of the residence time, which in the case of fast reservoir can be considered a proxy of the basin concentration time. The residence time in the slow and fast reservoir is assumed to range from $1 \mathrm{~h}$ to $240 \mathrm{~h}$ and $10 \mathrm{~h}$, respectively. The fraction of imperviousness $c_{0}$ varies between 0 , if there is no urbanization, and 1 , a condition in which all the surfaces are impermeable. The coefficient $c_{1}$ changes from 0 , if the all the percolated water contributes to the aquifer recharge, to 1 , if all the soil bucket leakages supply the slow reservoir.

To calibrate the model, different parameter sets $\theta\left[n Z r, s_{l}, s_{0}, K_{c}, K_{s}, K_{f}, c_{0}, c_{1}\right]$ were randomly generated through a Monte Carlo simulation, selecting the parameters from the previously described ranges. Among the different sets, only the first 20,000 with a NashSutcliffe efficiency NSE (Nash and Sutcliffe 1970) higher than zero in the calibration period have been retained and considered behavioural (Beven and Binley 1992). NSE is defined as:

$$
N S E=1-\frac{\sum_{i}^{N}\left(Q_{o u t i}-Q_{o b s i}\right)^{2}}{\sum_{i}^{N}\left(Q_{o b s i}-\overline{Q_{o b s}}\right)^{2}}
$$

where $Q_{o u t i}$ and $Q_{o b s i}$ are simulated and observed runoff at $i$-th time step, while $\overline{Q_{o b s}}$ is the average of the observed runoff and $N$ is the total number of time steps. NSE can vary between -inf and 1, where 1 indicates the perfect model representation of the observations. Considering only the simulations with $N S E>0$ ensures that only sets of parameters that lead to a high model performance are analysed. 


\section{Results and Discussion}

\subsection{Model Calibration and Reference Set of Parameters}

Through the Monte Carlo behavioural calibration, it was possible to obtain a set of parameters that ensure the highest performance in terms of NSE. For the investigated basins the maximum $N S E$ during the calibration period (NSE $=0.72$ in both cases) was achieved for the following parameter sets:

$$
\theta_{470}\left[n Z r, s_{l}, s_{0}, K_{c}, K_{s}, K_{f}, c_{0}, c_{1}\right]=[77.61,0.80,0.25,2.40,0.25,0.42,0.22,0.45]
$$

and

$$
\theta_{507}\left[n Z r, s_{l}, s_{0}, K_{c}, K_{s}, K_{f}, c_{0}, c_{1}\right]=[219.22,0.94,0.83,1.99,0.27,0.23,0.14,0.32] .
$$

However, as often reported in hydrologic literature, equifinality conditions are present (Beven and Freer 2001; Foulon and Rousseau 2018), implying that similar model performance (e.g. in terms of NSE) can be achieved by using different sets of parameters. To deal with this source of parametric uncertainty, out of the 20,000 behavioural Monte Carlo simulations, the best $5 \%$, corresponding to the 1000 simulations with the highest NSE, were retained and used with two aims. The first was to identify a reference set, taking into account the parameters' a posteriori distribution. At the same time, we used this restricted parameter ensemble to provide model output with parametric uncertainties.

Each model parameter cumulative probability distribution and the correspondent cumulative distribution weighted on the model performance $N S E$ have been plotted in Fig. 3. The terms $n Z r, s_{l}$ and $s_{0}$ were combined in one factor, $n Z r\left(s_{l}-s_{0}\right)$, which represents the amount of water that can be stored in the soil bucket. The analysis of Fig. 3 reveals that parameter cumulative distributions are quite different for the two considered basins. Once the influence of NSE is considered, the cumulative distribution weighted on the model performance (orange) departs from the unweighted one (red) if the model has relatively higher performances for some parameter ranges. Otherwise, the two cumulative distributions are close to each other, as is the case for the fast reservoir constant $K_{f}$.

The model parameter probability distribution was derived from the cumulative distribution weighted on NSE: reference parameter sets were chosen considering their modal values. The following reference sets were selected for the investigated basins:

$$
\theta_{470}\left[n Z r, s_{l}, s_{0}, K_{c}, K_{s}, K_{f}, c_{0}, c_{1}\right]=[100,0.91,0.3,1.7,0.55,0.39,0.29,0.38]
$$

and

$$
\theta_{507}\left[n Z r, s_{l}, s_{0}, K_{c}, K_{s}, K_{f}, c_{0}, c_{1}\right]=[100,0.78,0.35,1.8,0.25,0.18,0.3,0.35] .
$$

These data sets lead to an NSE equal to 0.7 for \#470 and to 0.69 for\#507 during the calibration period. In the validation period, the model performance is, as expected, a bit lower, corresponding to 0.65 and 0.33 , respectively. The lower performance during the validation period in the catchment \#507 could be due to the high climatological difference between the calibration and validation period. 

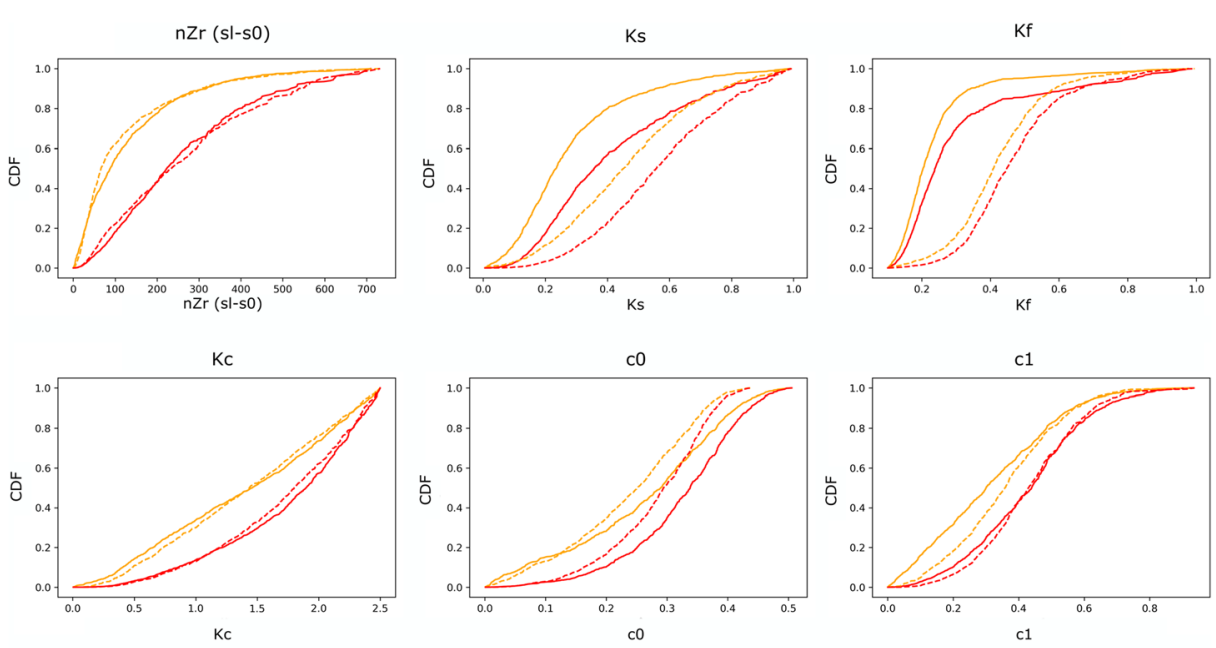

-- CDF weighted \#470- CDF weighted \#507
- CDF $\# 507$

Fig. 3 Cumulative probability distribution of each parameter for the best $5 \%$ simulations (orange) and weighted on the model performance NSE (red)

\subsection{Model Results}

Using the model outputs associated with the 5\%-best behavioural simulations, uncertainty bounds were evaluated and used to define an envelope of the 5\%-best model outputs. Fig. 4 illustrates, for both basins during calibration and validation periods, an example rainfall event (blue) and corresponding observed streamflow (red), simulated streamflow (black), obtained from the reference parameter set, and the 5\%-best simulation model output envelope (green shadow). The plots highlight that most of the observed streamflow falls within the envelope of the 5\%-best simulation model outputs: in particular 94\% (\#470) and 96\% (\#507) of the observed streamflow used for calibration is inside this envelope. For the validation period, $91 \%$ and $96 \%$ of the observations are contained in the 5\%-best simulation interval, respectively. Different envelopes, built from the $2.5 \%$ - and $7.5 \%$-best simulations, have been investigated, confirming the increase in the percentage of points falling within the envelopes as the percentage of simulations rises.

Simulated outflow results have also been compared with the one obtainable from the ecohydrological streamflow model EHSM proposed by Viola et al. (2014), where aquifer recharge processes are not considered and the entire leakage derived from the soil bucket feeds the slow reservoir. The percentage of points that fall inside the envelopes is almost the same for both models, highlighting the good reliability of EHSMu. Moreover, EHSMu shows a higher model performance in terms of NSE than EHSM: during the calibration period for EHSM, the maximum NSE is equal to 0.61 and 0.64 for \#470 and \#507 respectively, while using EHSMu the best simulation led to 0.72. The higher performance obtained with EHSMu underlines the importance of evaluating the aquifer recharge as a fundamental component in the water balance for urban catchments. 

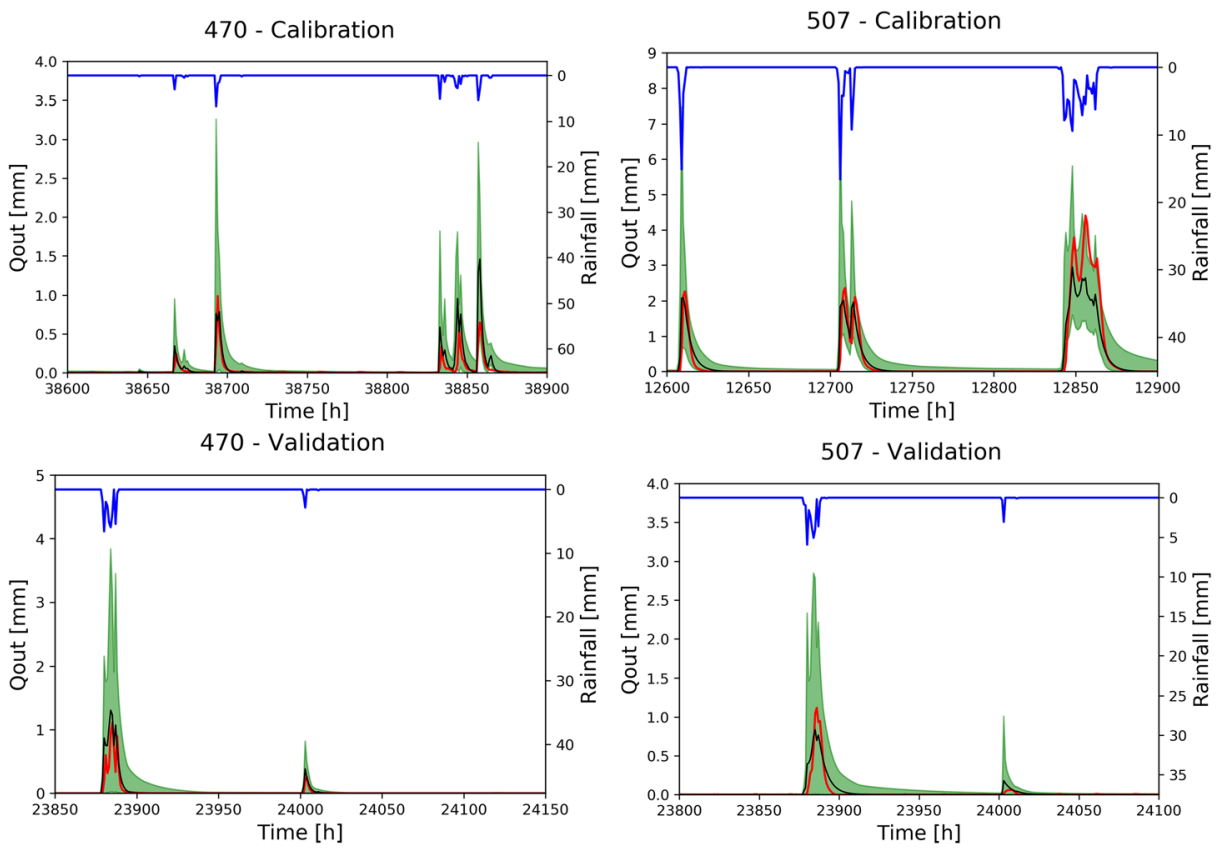

- Rainfall — Observed Qout — Reference Qout $\square$ Best Calibration Range

Fig. 4 Example of rainfall events and corresponding observed (red) and simulated streamflow obtained with the reference set (black) and 5\%-best simulation confidential interval (green areas) for the investigated basins, during calibration and validation period

\subsection{Long Term Water Balance}

EHSMu gives as outputs the runoff at the basin outlet, the actual evapotranspiration and the aquifer recharge at hourly time scale. We aggregated the water balance components over long time intervals to compare flux magnitude among calibration and validation

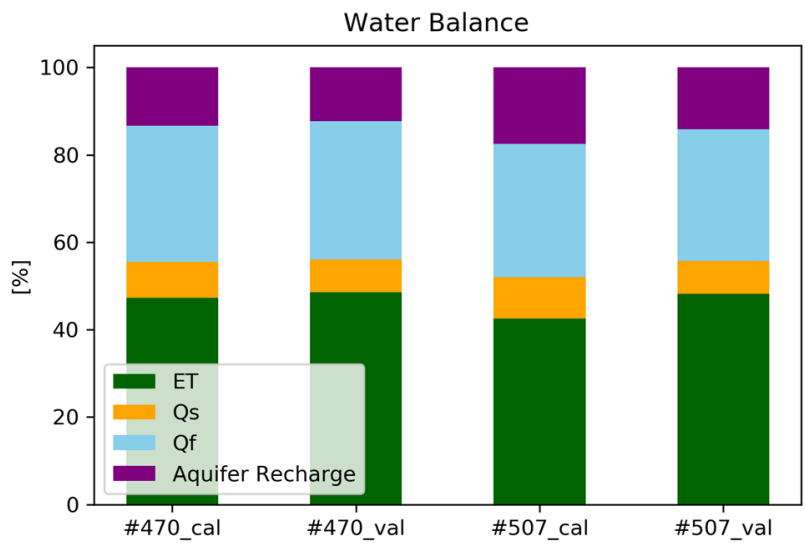

Fig. 5 Water Balance plotted for both basins, during the calibration and validation period using the reference parameter sets 
(a) Imperviousness coefficient $c_{0}$

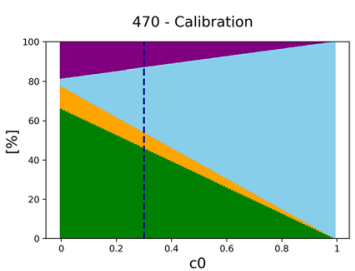

470 - Validation

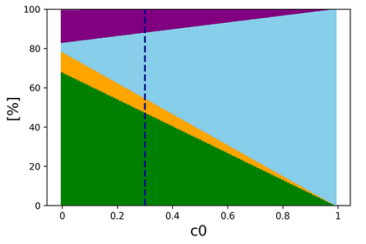

507 - Calibration

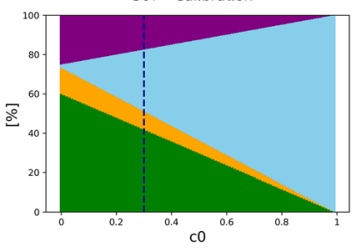

507 - Validation

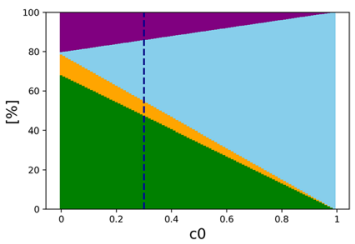

(b) Crop coefficient Kc

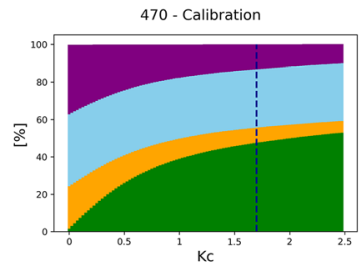

470 - Validation
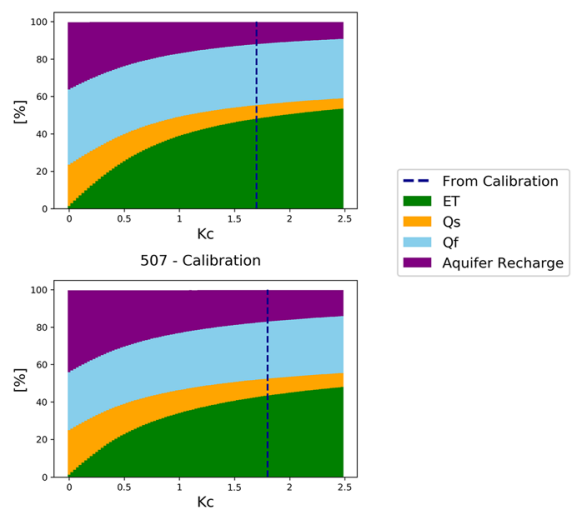

507 - Validation

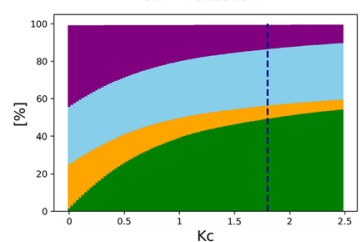

Fig. 6 Potential water balance variability corresponding to a variation of the imperviousness percentage $\mathrm{c}_{0}(\mathbf{a})$ and of the crop coefficient $\mathrm{K}_{\mathrm{c}}(\mathbf{b})$. Dashed blue line indicates the reference conditions obtained with $\theta_{470}\left[\mathrm{nZr}, \mathrm{s}_{\mathrm{l}}\right.$, $\left.\mathrm{s}_{0}, \mathrm{~K}_{\mathrm{c}}, \mathrm{K}_{\mathrm{s}}, \mathrm{K}_{\mathrm{f}}, \mathrm{c}_{0}, \mathrm{c}_{1}\right]=[100,0.91,0.3,1.7,0.55,0.39,0.29,0.38]$ and $\theta_{507}\left[\mathrm{nZr}, \mathrm{s}_{\mathrm{l}}, \mathrm{s}_{0}, \mathrm{~K}_{\mathrm{c}}, \mathrm{K}_{\mathrm{s}}, \mathrm{K}_{\mathrm{f}}, \mathrm{c}_{0}, \mathrm{c}_{1}\right]=[100$, $0.78,0.35,1.8,0.25,0.18,0.3,0.35]$. Potential water balance variability is plotted for both basins, during the calibration and validation period

periods and between the basins. Fig. 5 shows the water balance over the calibration and validation period for the investigated basins, highlighting evapotranspiration, slow and fast streamflow and aquifer recharge as a percentage of the cumulated rainfall. Evapotranspiration corresponds to about $45 \%$ in all considered scenarios, $15 \%$ is composed of aquifer recharge and the runoff at the basin outlet is $40 \%$, divided in $10 \%$ slow streamflow and $30 \%$ fast streamflow.

Water balance during the calibration period for basin \#507 is slightly different, since it presents a lower $(40 \%$ instead of $45 \%)$ total evapotranspiration and consequently a higher aquifer recharge. This is probably due to the statistical properties of rainfall: for the basin \#507, in the calibration period there are less but more intense rainfall events than in the validation period. This implies higher leakages from the soil bucket, with a consequent increase of the aquifer recharge and slow streamflow components and at the same time less evapotranspiration. 


\subsection{Land Use and Land Cover Changes}

In this section, we analyse and discuss the potential impact of land use and land cover changes on the water balance of the Charlotte metropolitan area. The reference parameter sets have been used as zero scenario and variations of the imperviousness and crop coefficients are investigated.

The presence of houses, roads and car parks within an urban catchment is represented by the EHSMu with the imperviousness coefficient $c_{0}$, which was chosen as equal to 0.29 for $\# 470$ and to 0.30 for \#507 in the reference parameter sets $\theta_{470}$ and $\theta_{507}$. These values are a good representative of the actual land use scenario presented in Fig. 2b, where about $30 \%$ of the surface presents a medium- or high-intensity development. To estimate the impact of land use changes on the urban basin water balance, a sensitivity analysis of $c_{0}$ was performed.

Figure 6a illustrates the percentages of each component of the water balance, as discussed in Section 3.3, estimated using the following reference parameter sets where $c_{0}$ varies from 0 to 1:

$$
\theta_{470}=\left[100,0.91,0.3,1.7,0.55,0.39, c_{0}, 0.38\right]
$$

and

$$
\theta_{507}=\left[100,0.78,0.35,1.8,0.25,0.18, c_{0}, 0.35\right] \text { with } c_{0} \in[0,1] .
$$

In Fig. 6a, the blue dashed line indicates the zero scenario. Values higher than 0.3 represent a potential future scenario, where the urbanization and the presence of high-density buildings are increased. For these scenarios, a higher percentage of fast runoff is expected, with a corresponding decrease of evapotranspiration and aquifer recharge. Results highlight how aquifer recharge, slow streamflow and evapotranspiration processes linearly decrease with higher values of the imperviousness fraction. Aquifer recharge is slightly higher in the larger basin (\#507), where it could constitute $20-25 \%$ of the water balance, in the case of a no impervious surface: this can be due to the lower $c_{1}$ coefficient, which defines the percentage of leakage that feeds the slow linear reservoir.

The potential impact of vegetation coverage changes is evaluated by investigating different values of the crop coefficient $K_{c}$. Fig. $6 \mathrm{~b}$ investigates the potential impact on the water balance of possible future variations of the vegetation type, represented through a perturbation of $K_{c}$ :

$$
\theta_{470}=\left[100,0.91,0.3, K_{c}, 0.55,0.39,0.29,0.38\right]
$$

and

$$
\theta_{507}=\left[100,0.78,0.35, K_{c}, 0.25,0.18,0.3,0.35\right] \text { with } K_{c} \in[0,2.5] .
$$

Lower values of $K_{c}$ represent vegetation with a low evapotranspiration rate, such as cacti and succulent plants. In this scenario, evapotranspiration decreases with a corresponding increase in aquifer recharge and slow streamflow. Fast streamflow, instead, is not affected by crop coefficient and variations in the total outflow are caused only by increase in the slow runoff component. This is clearly observable in all the cases investigated in Fig. 6a: slow streamflow generally varies from being more than $20 \%$ of the total water balance, when $K_{c}=0$, to 7-8\%, for $K_{c}=2.5$. Aquifer recharge is also strongly influenced by the crop coefficient, varying between $35 \%$ to $10 \%$ for catchment $\# 470$, and from $40 \%$ to $15 \%$ for the larger basin. 


\section{Conclusions and Future Works}

This work presented a new lumped conceptual ecohydrological streamflow model for urban areas that combines hydrological and ecological processes to estimate the runoff generation at the basin outlet at hourly scale. EHSMu was calibrated for two densely-urbanized catchments in the Charlotte metropolitan area. The 8 parameters that characterize the model were calibrated through Monte Carlo simulations, considering a subset of 20,000 runs with a NSE higher than zero. The model shows good performance, reaching a NSE equal to 0.72 in both basins: this underlines the importance of including the aquifer recharge component in the hydrological analysis and of evaluating in depth soil moisture dynamics in relation to evapotranspiration.

The water balance, analysed considering a reference set of parameters, highlighted that $45 \%$ of rainfall is lost due to evapotranspiration processes and $15 \%$ is directed to the aquifer. The runoff at the basin outlet, corresponding to $40 \%$ of the total rainfall, is composed of $25 \%$ of slow runoff derived from the soil bucket leakages and $75 \%$ of fast runoff from impermeable and saturated permeable surfaces.

The sensitivity analysis on the impacts of potential land use changes highlighted the drastic implication of an increase of imperviousness degree. Evapotranspiration, aquifer recharge and slow runoff linearly decrease for high imperviousness values, while the fast runoff largely increases. On the other hand, installing plants with a higher crop coefficient and faster metabolism will lead to an increment in evapotranspiration losses, with a consequent reduction in aquifer recharge and slow runoff.

This work aimed to present a conceptual model to estimate the runoff generation in urban areas. The model performance, however, could be further investigated using multiple indicators. Moreover, several different catchments should be evaluated in order to analyse the potential applicability of the EHSMu model to basins with different land use and land cover and located in different climatological regions.

Acknowledgements Open access funding provided by Università degli Studi di Cagliari within the CRUICARE Agreement.

Availability of Data and Material Land use and land cover data are available from the American National Land Cover Dataset NLCD (http://www.mrlc.gov/). Rainfall and streamflow data have been downloaded from the United States Geological Survey. Temperature data have been derived from the Global Historical Climate Network.

Code Availability Costume code.

Funding This work was partially supported by the Sardinian Region with law 7/2007 (funding call 2017, project: "HYDROSARD: Un approccio multidisciplinare integrato e multiscala per la valutazione globale delle risorse idriche nella Regione Sardegna, anche in condizioni di cambiamento climatico", CUP: F76C18000920002) and by the Fondazione di Sardegna (funding call 2017, project: Impacts of climate change on water resources and floods, CUP: F71117000270002).

\section{Compliance with Ethical Standards}

Conflicts of Interest/Competing Interests The authors declare no competing interests.

Open Access This article is licensed under a Creative Commons Attribution 4.0 International License, which permits use, sharing, adaptation, distribution and reproduction in any medium or format, as long as you give 
appropriate credit to the original author(s) and the source, provide a link to the Creative Commons licence, and indicate if changes were made. The images or other third party material in this article are included in the article's Creative Commons licence, unless indicated otherwise in a credit line to the material. If material is not included in the article's Creative Commons licence and your intended use is not permitted by statutory regulation or exceeds the permitted use, you will need to obtain permission directly from the copyright holder. To view a copy of this licence, visit http://creativecommons.org/licenses/by/4.0/.

\section{References}

Al-Janabi AMS, Yusuf B, Ghazali AH (2019) Modeling the Infiltration Capacity of Permeable Stormwater Channels with a Check Dam System. Water Resour Manag 33:2453-2470. https://doi.org/10.1007/s11269019-02258-z

Allen RG, Pereira LS, Raes D, Smith M (1998) Crop evapotranspiration-Guidelines for computing crop water requirements-FAO Irrigation and drainage paper 56. Fao, Rome, 300:9, D05109

Aronica G, Cannarozzo M (2000) Studying the hydrological response of urban catchments using a semidistributed linear non-linear model. J Hydrol 238:35-43. https://doi.org/10.1016/S0022-1694(00)00311-5

Asbjornsen $\mathrm{H}$ et al (2011) Ecohydrological advances and applications in plant-water relations research: a review. J Plant Ecol 4:3-22. https://doi.org/10.1093/jpe/rtr005

Bermúdez M, Ntegeka V, Wolfs V, Willems P (2018) Development and Comparison of Two Fast Surrogate Models for Urban Pluvial Flood Simulations. Water Resour Manag 32:2801-2815. https://doi.org/10.1007 /s11269-018-1959-8

Berne A, Delrieu G, Creutin J-D, Obled C (2004) Temporal and spatial resolution of rainfall measurements required for urban hydrology. J Hydrol 299:166-179. https://doi.org/10.1016/j.jhydrol.2004.08.002

Beven K, Binley A (1992) The future of distributed models: Model calibration and uncertainty prediction. Hydrol Process 6:279-298. https://doi.org/10.1002/hyp.3360060305

Beven K, Freer J (2001) Equifinality, data assimilation, and uncertainty estimation in mechanistic modelling of complex environmental systems using the GLUE methodology. J Hydrol 249:11-29. https://doi.org/10.1016 /S0022-1694(01)00421-8

Botter G, Porporato A, Rodriguez-Iturbe I, Rinaldo A (2007) Basin-scale soil moisture dynamics and the probabilistic characterization of carrier hydrologic flows: Slow, leaching-prone components of the hydrologic response. Water Resour Res 43:43. https://doi.org/10.1029/2006wr005043

Chow VT (1964) Handbook of applied hydrology: a compendium of water-resources technology. Ed. McGrawhill, New York

Clapp RB, Hornberger GM (1978) Empirical equations for some soil hydraulic properties. Water Resour Res 14: 601-604. https://doi.org/10.1029/WR014i004p00601

Cristiano E, ten Veldhuis MC, van de Giesen N (2017) Spatial and temporal variability of rainfall and their effects on hydrological response in urban areas - a review. Hydrol Earth Syst Sci 21:3859-3878. https://doi. org/10.5194/hess-21-3859-2017

Cristiano E, Ten Veldhuis M-C, Wright DB, Smith JA, van de Giesen N (2019) The Influence of Rainfall and Catchment Critical Scales on Urban Hydrological Response Sensitivity. Water Resour Res 55:3375-3390. https://doi.org/10.1029/2018wr024143

Farg E, Arafat SM, Abd El-Wahed MS, El-Gindy AM (2012) Estimation of evapotranspiration ETc and crop coefficient Kc of wheat, in South Nile Delta of Egypt using integrated FAO-56 approach and remote sensing data. Egypt J Remote Sens Space Sci 15:83-89. https://doi.org/10.1016/j.ejrs.2012.02.001

Fletcher TD, Andrieu H, Hamel P (2013) Understanding, management and modelling of urban hydrology and its consequences for receiving waters: a state of the art. Adv Water Resour 51:261-279. https://doi.org/10.1016 /j.advwatres.2012.09.001

Foulon É, Rousseau AN (2018) Equifinality and automatic calibration: what is the impact of hypothesizing an optimal parameter set on modelled hydrological processes? Canadian Water Resources Journal / Revue canadienne des ressources hydriques 43:47-67. https://doi.org/10.1080/07011784.2018.1430620

Grimmond CSB et al (2010) The international urban energy balance models comparison project: first results from phase 1. J Appl Meteorol Climatol 49:1268-1292. https://doi.org/10.1175/2010jamc2354.1

Guerra E, Ventura F, Snyder RL (2016) Crop Coefficients: A Literature Review. J Irrig Drain Eng 142: 06015006. https://doi.org/10.1061/(ASCE)IR.1943-4774.0000983

Hale MG, Orcutt DM (1987) The physiology of plants under stress. John Wiley \& Sons, Chichester

Jakeman AJ, Littlewood IG, Whitehead PG (1990) Computation of the instantaneous unit hydrograph and identifiable component flows with application to two small upland catchments. J Hydrol 117:275-300. https://doi.org/10.1016/0022-1694(90)90097-H 
Laio F, Porporato A, Ridolfi L, Rodriguez-Iturbe I (2001) Plants in water-controlled ecosystems: active role in hydrologic processes and response to water stress: II. Probabilistic soil moisture dynamics Advances in Water Resources 24:707-723. https://doi.org/10.1016/S0309-1708(01)00005-7

Li C (2012) Ecohydrology and good urban design for urban storm water-logging in Beijing, China. Ecohydrol Hydrobiol 12:287-300. https://doi.org/10.2478/v10104-012-0029-8

Liu M, Tian H, Yang Q, Yang J, Song X, Lohrenz SE, Cai W-J (2013) Long-term trends in evapotranspiration and runoff over the drainage basins of the Gulf of Mexico during 1901-2008. Water Resour Res 49:19882012. https://doi.org/10.1002/wrcr.20180

Marchionni V, Revelli R, Daly E (2019) Ecohydrology of urban ecosystems. In Dryland Ecohydrology, Springer International Publishing, Cham, pp 533-571. https://doi.org/10.1007/978-3-030-23269-6_20

Meili $\mathrm{N}$ et al (2020) An urban ecohydrological model to quantify the effect of vegetation on urban climate and hydrology (UT\&amp;C v1.0). Geosci Model Dev 13:335-362. https://doi.org/10.5194/gmd-13-335-2020

Menne MJ, Durre I, Vose RS, Gleason BE, Houston TG (2012) An Overview of the Global Historical Climatology Network-Daily Database. J Atmos Ocean Technol 29:897-910. https://doi.org/10.1175/jtechd-11-00103.1

Nash JE, Sutcliffe JV (1970) River flow forecasting through conceptual models part I - A discussion of principles. J Hydrol 10:282-290. https://doi.org/10.1016/0022-1694(70)90255-6

Pina RD, Ochoa-Rodriguez S, Simões NE, Mijic A, Marques AS, Maksimović Č (2016) Semi- vs. Fullydistributed urban stormwater models: model set up and comparison with two real case studies. Water 8:58. https://doi.org/10.3390/w8020058

Pumo D, Viola F, Noto LV (2008) Ecohydrology in Mediterranean areas: a numerical model to describe growing seasons out of phase with precipitations. Hydrol Earth Syst Sci 12:303-316. https://doi.org/10.5194/hess-12303-2008

Rodriguez-Iturbe I, Porporato A, Ridolfi L, Isham V, Coxi DR (1999) Probabilistic modelling of water balance at a point: the role of climate, soil and vegetation proceedings of the Royal Society of London series a: mathematical. Phys Eng Sci 455:3789-3805. https://doi.org/10.1098/rspa.1999.0477

Rubinato M, Shucksmith J, Saul AJ, Shepherd W (2013) Comparison between InfoWorks hydraulic results and a physical model of an urban drainage system. Water Sci Technol 68:372-379. https://doi.org/10.2166 /wst.2013.254

Salvadore E, Bronders J, Batelaan O (2015) Hydrological modelling of urbanized catchments: A review and future directions. J Hydrol 529:62-81. https://doi.org/10.1016/j.jhydrol.2015.06.028

Sarma PBS, Delleur JW, Rao AR (1973) Comparison of rainfall-runoff models for urban areas. J Hydrol 18:329347. https://doi.org/10.1016/0022-1694(73)90056-5

Shields C, Tague C (2015) Ecohydrology in semiarid urban ecosystems: Modeling the relationship between connected impervious area and ecosystem productivity. Water Resour Res 51:302-319. https://doi. org/10.1002/2014wr016108

ten Veldhuis M-C, Zhou Z, Yang L, Liu S, Smith J (2018) The role of storm scale, position and movement in controlling urban flood response. Hydrol Earth Syst Sci 22:417-436

Thornthwaite CW (1948) An approach toward a rational classification of climate. Geogr Rev 38:55-94

UN Desa (2019) World population prospects 2019: Highlights. United Nations Department for Economic and Social Affairs, New York

Versini P-A, Gires A, Tchinguirinskaia I, Schertzer D (2016) Toward an operational tool to simulate green roof hydrological impact at the basin scale: a new version of the distributed rainfall-runoff model Multi-Hydro. Water Sci Technol 74:1845-1854. https://doi.org/10.2166/wst.2016.310

Vico G, Revelli R, Porporato A (2014) Ecohydrology of street trees: design and irrigation requirements for sustainable water use. Ecohydrology 7:508-523. https://doi.org/10.1002/eco.1369

Viola F, Daly E, Vico G, Cannarozzo M, Porporato A (2008) Transient soil-moisture dynamics and climate change in Mediterranean ecosystems. Water Resour Res 44:44. https://doi.org/10.1029/2007wr006371

Viola F, Pumo D, Noto LV (2014) EHSM: a conceptual ecohydrological model for daily streamflow simulation. Hydrol Process 28:3361-3372. https://doi.org/10.1002/hyp.9876

Wright DB, Smith JA, Baeck ML (2014) Flood frequency analysis using radar rainfall fields and stochastic storm transposition. Water Resour Res 50:1592-1615. https://doi.org/10.1002/2013wr014224

Zabret K, Šraj M (2019) Rainfall interception by urban trees and their impact on potential surface runoff CLEAN - soil. Air Water 47:1800327. https://doi.org/10.1002/clen.201800327

Zoppou C (2001) Review of urban storm water models. Environ Model Softw 16:195-231. https://doi. org/10.1016/S1364-8152(00)00084-0

Publisher's Note Springer Nature remains neutral with regard to jurisdictional claims in published maps and institutional affiliations. 